\title{
Estimation of CPI of Some Sub-sahara African Countries: Panel Data Approach
}

\author{
Oyekunle Janet Olufunmike ${ }^{1}$, Ayoola Joshua Femi ${ }^{2}$, Oyenuga Iyabode Favour ${ }^{3}$, \\ Masopa Adekunle Nurudeen ${ }^{1}$, Adesiyan Adefowope Abdul Azeez ${ }^{1}$ \\ ${ }^{1}$ Department of Statistics, Federal Polytechnic, Ede, Nigeria \\ ${ }^{2}$ Department of Statistics, University of Ibadan, Ibadan, Nigeria \\ ${ }^{3}$ Department of Mathematics and Statistics, the Polytechnic, Ibadan, Nigeria
}

Email address:

Oyekunle.olufunmike@yahoo.com (O. J. Olufunmike), ayoolafemi@yahoo.com (A. J. Femi), ioyenuga2007@polyibadan.edu.ng (O. I. Favour)

\section{To cite this article:}

Oyekunle Janet Olufunmike, Ayoola Joshua Femi, Oyenuga Iyabode Favour, Masopa Adekunle Nurudeen, Adesiyan Adefowope Abdul Azeez. Estimation of CPI of Some Sub-sahara African Countries: Panel Data Approach. American Journal of Theoretical and Applied Statistics. Vol. 8, No. 6, 2019, pp. 246-252. doi: 10.11648/j.ajtas.20190806.16

Received: July 13, 2019; Accepted: October 31, 2019; Published: November 15, 2019

\begin{abstract}
One of the economic indicators that are necessary to provide information on the state and progress of country is the Consumer Price Index (CPI) which measures changes in the price of goods and services over a certain period of time. An effective monetary policy depends on the ability of economists to develop a reliable model that could understand the ongoing economic processes and predict future developments. Hence, this study is aimed at estimating CPI (a component of Inflation) in 20 Sub-Sahara African (SSA) countries in relation to Broad Money (BM), Export Rate (EXP), Gross Domestic Product (GDP) and Private Consumption Expenditure (PCE) using panel data approach. The data was extracted from the World Bank Data Bank for a period of 30 years (1987-2016). The Fixed Effect Model (FEM) was employed and the model summary was computed using the panel least squares. The Variance Inflation Factor (VIF) was used to test for the presence of multicollinearity. The result of the analysis shows that the CPI for SSA countries ranges from $0.0007 \%$ to $298.51 \%$ $(2010=100)$ with an average of $59.76 \%$. All the predictors included in estimating the CPI have significant effect at $5 \%$ level except the GDP. The estimated panel regression equation is $C P I_{i t}=71.4449-0.1735 B M_{i t}-0.3309 E X P_{i t}+7.4338 e-$ $12 G D P_{i t}+1.1335 e-10 P C E_{i t}$. The estimated coefficient of determination is 0.853 which means that $85.3 \%$ of the total variation in CPI can be accounted for by the variations in the macroeconomic variables included. The VIF for all the variables is less than 3.o meaning that there is no sign of multicollinearity and therefore, there is no correlation among the predictors. It was concluded that the FEM estimated can be used to assess the behavior of the CPI in the nearest future. Moreover, $85.3 \%$ of the variations in CPI can be explained by the economic variables used as independent variables. It is recommended that efforts should be geared towards improving the input of these variables in the economy such that appropriate relationship will exist between them and the CPI in the SSA nations.
\end{abstract}

Keywords: CPI, SSA, PCE, EXP, GDP

\section{Introduction}

\subsection{Background}

The economy of any nation is of great importance to the government, business and the entire populace. It is therefore pertinent that relevant economic indicators are available to inform on the state, growth and progress of the economy. The CPI is a statistical estimate constructed using the prices of a sample of representative items whose prices are collected periodically. Sub-indices and sub-sub-indices are computed for different categories and sub-categories of goods and services, being combined to produce the overall index with weights reflecting their shares in the total of the consumer expenditures covered by the index. It is one of the several price indices calculated by most national statistical agencies. The annual percentage change in CPI is used as a measure of inflation. The index is usually computed monthly, or 
quarterly in some countries, as a weighted average of subindices for different components of consumer expenditure, such as food, housing, shoes, clothing, each of which is in turn a weighted average of sub-sub-indices.

The importance of CPI to any nation cannot be overemphasized. This is because, it can be used to index the real value of wages and salaries; it is one of the most frequently used statistics for identifying period of inflation and deflation. The economic strength of a country can be determined with adequate information on the CPI. Based on its relevance, the CPI has been considered as one of the national economic statistic to be closely monitored.

Other variables that are of concern are Broad Money, Gross Domestic Product, Private Consumption Expenditure and Exports of goods and Services. Efforts to formulate a macro-economic model of Consumer Price Index or inflation is not new in literature. Many attempts have been made by several scholars to explain the working of a country's economy from the perspective of this variable.

The study [1] fitted a Seasonal Autoregressive Integrated Moving Average (SARIMA) model to the monthly data of Nigeria Consumer Price Index over a period of 1996 - 2013. It was discovered that SARIMA $(1,2,1)(0,0,1)_{12}$ best fits the data. Forecasts made using the model and the scientific comparison carried out showed that there is no significant difference between the observed and the forecast values of CPI data.

The study [2] examined the effects of money supply $\left(\mathrm{M}_{2}\right)$ and exchange rates on inflation in Nigeria, as measured by the Consumer Price Index for a period of 28 years (1982 to 2009). A multiple regression analysis was carried out to model inflation (CPI) as dependent variable while money supply and exchange rate were the independent variable. It was discovered that the two macro-economic variables have varying degree of impact on inflation.

The study [3] employs a plain inflation macroeconomic model to empirically examine the CPI inflation determinants for Vietnam over the time span 2001 - 2009. The major concern is to investigate the relationships among exchange rate, the prices of crude oil, rice and inflation. They employed time series evaluation methods, they discovered that the supply of money, rice prices as well as oil prices are the significant determinants of CPI inflation.

The researcher [4] studied the significance of macroeconomic variables such as broad money, gross domestic product and household final consumption expenditure towards the Consumer Price Index in Malaysia on long run economy. The long run relationship between dependent and independent variables was estimated on the vector Error correction (VEC) model. The independent variables were found to be significantly positively related to the Consumer Price Index. Saravanan's study is thus a motivation for this research where the aim is to see the relationship between $\mathrm{CPI}$ and these macroeconomic variables via a panel data model.

The study [5] examined the relationship between money, represented by $\mathrm{M} 1$, and prices represented by $\mathrm{CPI}$ in
Alabania using monthly data from 2000 to 2015. The tool of econometrics was employed and the Johansen co integration test was implemented to correctly disclose the relationship between $\mathrm{M} 1$ and inflation (prices). The result shows a positive relationship between the variable indicating that an increase in money supply would consequently lead to increase in inflation (that is rise in prices of goods and services).

These studies [6-9] have all at one time or the other examined the relationship between CPI and GDP for many countries of the world using various statistical analysis. All these studies came out with the result that high inflation is and has never been favourable to economic growth.

The study [10] investigated monetary policy and financial inclusion in Sub-Sahara Africa using a panel VAR Approach. The findings show that a bi-causal relationship exists between monetary policy and financial inclusion. Therefore, promoting financial inclusion will require government in sub-Sahara Africa to reduce monetary policy rate.

\subsection{Sub-saharan African Countries}

Sub-Saharan Africa is, geographically, the area of the continent of Africa that lies south of the Sahara desert. SubSaharan Africa (SSA) means Africa south of the Sahara. It is sometimes referred to as the "Black Africa". The term is used by the United Nations, the IMF, the World Bank, the Economist, CNN, American think tanks, anthropologists and others.

Politically, it consists of all African countries that are fully or partially located south of the Sahara (excluding Sudan, even though Sudan sits in the Eastern portion of the Sahara desert. It contrasts with North Africa, which is considered a part of the Arab world. Somalia, Djibouti, Comoros and Mauritania are geographically part of Sub -Saharan Africa, but also part of the Arab world. https://en.wikipedia.org/.../Sub-Saharan_Africa.

The Sub-Saharan African countries had the fastest economic growth over the last ten years. The government and countries have enjoyed the greatest investment returns among the world's emerging markets. During the past ten years, the gross domestic product of the 11 largest Sub-Saharan countries increased 51\%, more than twice the world's $23 \%$ and almost four times the $13 \%$ expansion of the US; the largest economy, according to data compiled by Bloomberg. The robust expansion being accompanied by stabilizing inflation on the African continent, with the CPI for all Africa declining to $7.8 \%$ from more than $13 \%$ in 2008 and the continents CPI remaining less than $8 \%$ since 2013 (Bloomberg data show).

The combination of torrid growth and diminished inflation is proving an irresistible lure for global investors, who have seen the opposite trends plague the biggest emerging-market countries; Brazil, Russia, India and China.

The researcher [11] carried out a study on the drivers of inflation in sub-Saharan African countries using a Global VAR model which incorporates trade and financial linkages among economies, as well as the role of regional and global 
demand and inflationary spillovers. The study covers a total of 65 countries; comprising of 8 Euro area grouped together (based on their PPP-GDP weights), as well as 14 CFA countries and 33 other countries modeled individually. The GVAR model, therefore contains 35 countries/regions. The data used are quarterly data from 1981-2013 consisting of CPI, Nominal Effective Exchange Rate (NEER), Broad Money (BM), Nominal Interest Rate (either deposit or discount rate) (NIR) and Real Gross Domestic Product (RGDP); as well as global oil and food prices.

It was found that in the past 25 years, the main drivers of inflation have been domestic supply shocks and shocks to exchange rate and monetary variables, but that in recent years, the contributions of these shocks to inflation has fallen. As the region becomes more integrated with the global economy, however, the role of global oil and food shocks as well as inflation spillovers from other countries have increased. The importance of regional and global demand shocks have increased as well. This implies that policy makers in the region should be more cautious to the global inflation and growth developments.

Table 1. List of 20 Sub Sahara African Countries Codes as used by the World Bank.

\begin{tabular}{lll}
\hline KEY NOTE & CODE & COUNTRY \\
\hline AGO & 1 & ANGOLA \\
BDI & 2 & BURUNDI \\
CPV & 3 & CAPE VERDE \\
TCD & 4 & CHAD \\
COM & 5 & COMOROS \\
GAB & 6 & GABON \\
GHA & 7 & GHANA \\
GIN & 8 & GUINEA \\
MRT & 9 & MAURITANIA \\
NGA & 10 & NIGERIA \\
RWA & 11 & RWANDA \\
SEN & 12 & SENEGAL \\
SLE & 13 & SIERRA LEONE \\
ZAF & 14 & SOUTH AFRICA \\
SDN & 15 & SUDAN \\
SWZ & 16 & SWAZILAND \\
TZA & 17 & TANZANIA \\
UGA & 18 & UGANDA \\
ZMB & 19 & ZAMBIA \\
ZWE & 20 & ZIMBABWE \\
\hline
\end{tabular}

NOTE: The countries are arranged in alphabetical order without any preference to any country.

\section{Materials and Methods}

Different types of data are generally available for empirical analysis, namely, time series, cross section, and panel. A data set containing observations on a single phenomenon observed over multiple time periods is called time series (e.g. all item consumer price index for several years). In time series data, both the values and the ordering of the data points have meaning. In cross-section data, values of one or more variables are collected for several sample units, or entities, at the same point in time (e.g. CPI for $15 \mathrm{sub}$ Saharan African countries for a given year).
Panel data sets refer to sets that consist of both time series and cross section data. This has the effect of expanding the number of observations available, for instance if we have 32 years of data across 15 countries, we have 510 observations. Although there would not be enough to estimate the model as a time series or a cross section, there would be enough to estimate it as a panel. However, in this paper, the panel data model is preferred to time series and cross section model.

In a typical symbolic representation, time series variables are usually denoted by subscript $t$ while cross-sectional variables are denoted by subscript $i$.

Since panel data have both time series and cross-sectional dimensions, their variables are represented by subscript it. Using the proposed model for this research, It can specify the following models in respect of this data set below:

$$
\begin{gathered}
y_{t}=\alpha+\sum_{w=1}^{k} \beta_{w} X_{w t}+U_{t} t=1,2, \ldots, T \\
y_{i}=\alpha+\sum_{w=1}^{k} \beta_{w} X_{w i}+U_{i} i=1,2, \ldots, n \\
y_{i t}=\alpha+\sum_{w=1}^{k} \beta_{w} X_{w i t}+U_{i t} i=1,2, \ldots, n t=1,2, \ldots, T
\end{gathered}
$$

where y denotes, CPI, X represents the explanatory variables ( BM, GDP, PCE and EXP), $t$ is time series dimension, $i$ is the cross-sectional dimension and $w$ is a counter for the explanatory variable while $k$ is the number of the explanatory variable used. Equation (1) above follows a time series framework, equation (2) follows a cross-sectional frame work while equation (3) follows a panel data framework. Drukker, D. M. (2003).

\subsection{Panel Data Predictive Model (PDPM)}

Panel data models are broadly divided into two namely Static Panel data models and Dynamic Panel Models. The most notable difference between the two models is the inclusion of the lagged dependent variable as a regressor in the latter. This exercise focuses on the static panel data models. A typical static panel data regression can be expressed as:

$$
y_{i t}=\alpha+\sum_{w=1}^{k} \beta_{w} X_{w i t}+e_{i t}
$$

In matrix form

$$
y_{i t}=\alpha+X^{\prime} \beta+e
$$

where

$$
\begin{aligned}
& w=1,2, \ldots, k \text { (Regressors) } \\
& i=1,2, \ldots, n \text { (Cross sectional units) } \\
& t=1,2, \ldots, T \text { (Time periods) }
\end{aligned}
$$

where: $\mathrm{Y}$ is the dependent variable and $X_{w}$ are the explanatory variables. The subscripts ' $\mathrm{i}$ ' and ' $\mathrm{t}$ ' as earlier 
defined refer to the cross-sectional dimension and time series dimension respectively, $e_{i t}$ is the composite error term which can be decomposed further into specific effects or individual observations (country effects as in the case of this research) and remainder disturbance term. There are two sets of specific effects namely; the individual specific effect and time specific effects. If only one set of specific effects is included in the regression, such is referred to as one-way error components model. However, if both sets of specific effects are included, we refer to the model as two-way error components model. Equations (6) and (7) show decomposition of $e_{i t}$ into one-way and two-way error components.

$$
\begin{gathered}
e_{i}=\mu_{i}+v_{i t} \\
e_{i t}=\lambda_{i}+v_{i t} \\
e_{i}=\mu_{i}+\lambda_{t}+v_{i t}
\end{gathered}
$$

where $\mu_{i}$ and $\lambda_{t}$ denote the unobserved individual and time specific effects respectively. We shall limit our empirical applications to the one-way error components.

\subsection{Estimation of Panel Data Models}

As earlier discussed, panel data has two dimensions namely: the individual dimension and time dimension. A panel data model differs from a cross-section or time series in that it has double subscript on its variables. That is, it's of the form:

$$
\begin{gathered}
y_{i t}=\alpha+\sum_{w=1}^{k} \beta_{w} X_{w i t}+e_{i t}=\alpha+X_{i t}^{\prime} \beta+e_{i t} \\
i=1,2, \ldots, n t=1,2, \ldots, T
\end{gathered}
$$

$i$ could denote individuals, households, firms, countries, etc. for the purpose of this paper, $i$ denotes countries while $t$ denotes time, $y_{i t}$ denotes the value of the dependent variable $\mathrm{y}$ for country $i$ at time $t$. $\alpha$ is a scalar, $\beta$ is $k \times 1$ matrix (a column vector) and $X_{i t}$ is the independent variable $\mathrm{X}$ for country $i$ at time $t$. Although, (9) postulates common intercept $(\alpha)$ for all $i$ and $t$ and common vector of slope coefficients for all $i$ and $t$, variants of the model exist.

The variants include:

$$
y_{i t}=\alpha_{i}+\sum_{w=1}^{k} \beta_{w} X_{w i t}+e_{i t}=\alpha_{i}+X_{i t}^{\prime} \beta+e_{i t}
$$

Equation (10) postulates constant slope coefficients and intercept that varies over countries.

$$
y_{i t}=\alpha_{i t}+\sum_{w=1}^{k} \beta_{w} X_{w i t}+e_{i t}=\alpha_{i t}+X_{i t}^{\prime} \beta+e_{i t}
$$

Equation (11) postulates constant slope coefficients and intercept that varies over countries and time.

$$
y_{i t}=\alpha_{i}+\sum_{w=1}^{k} \beta_{w i} X_{w i t}+e_{i t}=\alpha_{i t}+X_{i t}^{\prime} \beta_{i}+e_{i t}
$$

Equation (12) postulates intercept and slopes that vary

\begin{tabular}{|c|c|c|c|c|c|}
\hline & CPI & BM & EXP & GDP & PCE \\
\hline Mean & 59.76165 & 26.50362 & 29.13047 & $2.39 \mathrm{E}+10$ & $2.1 \mathrm{E}+10$ \\
\hline Median & 57.06336 & 22.07418 & 25.45668 & $4.94 \mathrm{E}+09$ & $3.96 \mathrm{E}+09$ \\
\hline Maximum & 298.5092 & 151.5489 & 100.949 & $5.69 \mathrm{E}+11$ & $3.71 \mathrm{E}+11$ \\
\hline Minimum & 0.0007 & 7.218083 & 3.335026 & $1.14 \mathrm{E}+08$ & 82647046 \\
\hline Std. Dev. & 38.68725 & 16.05336 & 18.50038 & $6.57 \mathrm{E}+10$ & $4.7 \mathrm{E}+10$ \\
\hline Skewness & 0.686119 & 2.40603 & 1.133996 & 4.880391 & 3.61084 \\
\hline Kurtosis & 4.865639 & 11.68028 & 4.070958 & 29.84607 & 17.47774 \\
\hline Probability & 0.000 & 0.000 & 0.000 & 0.000 & 0.000 \\
\hline Sum & 35856.99 & 15902.17 & 17478.28 & $1.44 \mathrm{E}+13$ & $1.26 \mathrm{E}+13$ \\
\hline Sum Sq. Dev. & 896525.2 & 154368.6 & 205016.1 & $2.59 \mathrm{E}+24$ & $1.32 \mathrm{E}+24$ \\
\hline Observations & 600 & 600 & 600 & 600 & 600 \\
\hline
\end{tabular}
over countries.

$$
y_{i t}=\alpha_{i t}+\sum_{w=1}^{k} \beta_{w i t} X_{w i t}+e_{i t}=\alpha_{i t}+X_{i t}^{\prime} \beta_{i t}+e_{i t}
$$

Equation (13) postulates intercept and slopes that vary over time and countries.

\section{Data Analysis and Discussion}

Table 2. Descriptive Statistics of Variables Used.

Source: Analysis Output

It can be seen from Table 2 that the average CPI is 59.76165, the average $\mathrm{BM}$ is 26.50362, the EXP is 29.13047 , the average GDP is $2.39 \mathrm{E}+10$, and the average $\mathrm{PCE}$ is $2.10 \mathrm{E}+10$. It is also evident that the consumer Index minimum ever attained is 0.0007 and the maximum ever attained is 298.5092. The standard deviation for the 600 dataset for Consumer Index is 38.68725 with skewness and kurtosis of 0.686119 and 4.865639 respectively which shows that the distribution of the population from which the data was selected is positively 
skewed and highly peaked since the coefficient of skewness is greater than zero and kurtosis is greater than 3. The Jarque-Bera statistic also confirmed that regression errors are normally distributed because of the significant p-value which leads to the rejection of the null hypothesis that the population distribution is normal.

Test for Multicollinearity

The table below shows SPSS output for the pooled regression model using OLS. The parameters are estimated with their test for significance. Collinearity Statistics which computed the Variance Inflation Factor (VIF) is a good test for multicollinearity. The VIF for each of the explanatory variable is less than 5 which make it very obvious that there is no multicollinearity in the set of data.

In order to establish statement about predictors included in Sub Sahara African nations' consumer index was tested for the multicollinearity in the pooled regression model using ordinary least square (OLS).

Table 3. Parameter Estimation and Variance Inflation.

\begin{tabular}{|c|c|c|c|c|c|c|c|}
\hline \multirow{2}{*}{ Model } & \multicolumn{2}{|c|}{ Unstandardized Coefficients } & \multirow{2}{*}{$\begin{array}{l}\text { Standardized Coefficients } \\
\text { Beta }\end{array}$} & \multirow{2}{*}{$\mathbf{T}$} & \multirow{2}{*}{ Sig. } & \multicolumn{2}{|c|}{ Collinearity Statistics } \\
\hline & B & S. E & & & & Tolerance & VIF \\
\hline Constant & 39.807 & 3.668 & & 10.853 & $.000^{*}$ & & \\
\hline $\mathrm{BM}$ & .346 & .100 & .144 & 3.469 & $.001^{*}$ & .874 & 1.144 \\
\hline EXP & .226 & .083 & .108 & 2.728 & $.007^{*}$ & .957 & 1.045 \\
\hline GDP & $-4.584 \mathrm{E}-12$ & .000 & -.008 & -.124 & $.901^{*}$ & .380 & 2.635 \\
\hline PCE & $2.055 \mathrm{E}-10$ & .000 & .250 & 4.039 & $.000^{*}$ & .393 & 2.546 \\
\hline
\end{tabular}

$* \mathrm{p}<0.05$ at $5 \%$ significant level

The coefficient table above is a result from SPSS output using OLS to estimate the parameters. It shows that BM, EXP and PCE are significant at 5\% level while GDP is not significant at $5 \%$ level. The VIF for each explanatory variable shows that none of them has its variance being inflated by up to a factor of 3.0. This shows that there is no correlation among the explanatory variables. Hence, no sign of presence of multicollinearity in the dataset.

Table 4. Model Summary of the Pooled Regression Model.

\begin{tabular}{llllll}
\hline Model Summary $^{\mathbf{b}}$ & & & & \\
\hline Model & R & R Square & Adjusted R Square & Std. Error of the Estimate & Durbin-Watson \\
\hline 1 & $0.328^{\mathrm{a}}$ & 0.108 & 0.102 & 36.66589 & .393 \\
\hline
\end{tabular}

a. Predictors: (Constant), BM, EXP, GDP, PCE

b. Dependent Variable: CPI

The model above shows that the coefficient of determination $\left(\mathrm{R}^{2}\right)$ is 0.11 with standard error 36.67 , meaning that $11 \%$ of the total variation in CPI could be explained by the variations in BM, EXP, GDP, and PCE while $89 \%$ could be explained by other variables not used in the model. The model is efficient because the standard error is moderate. Since there is no multicollinearity, it would have been a good test but for the cross sectional effects, that would be tested to see if it is significant or not. However, the pooled regression model does not show the cross section effect of the panel data. It is useful for the fixed effect model for the estimation of the parameters and test for the significant of the cross section effect.
Table 5. Fixed Effect Panel Data Model Estimates.

\begin{tabular}{lllll}
\hline Variable & Coefficient & Std-Error & t- Statistic & Prob. \\
\hline C & 71.4449 & 3.4887 & 20.4792 & $1.30 \mathrm{E}-69$ \\
BM & -0.1735 & 0.0787 & -2.2054 & 0.03 \\
EXP & -0.3309 & 0.0861 & -3.8449 & 0.000 \\
GDP & $7.4338 \mathrm{E}-12$ & 2.5879 & 0.2873 & 0.77 \\
PCE & $1.1335 \mathrm{E}-10$ & 4.0126 & 2.8250 & 0.005 \\
\hline
\end{tabular}

Dependent Variable: CPI

Method: Panel Least Squares

Sample: 19872016

Periods Included: 30

Cross-sections included: 20

Total panel (balanced) observations: 600

Source: Analysis Output

Table 6. Effects Specification.

\begin{tabular}{llll}
\hline R-Squared & $\mathbf{0 . 8 5 2 5}$ & Mean Dependent Variable & $\mathbf{5 9}$ \\
\hline Adjusted & 0.8385 & S. D. Dependent Variable & 38.6872 \\
S. E. OF Regression & 15.4702 & Sum Squared Residual & 132215.2433 \\
F-Statistic & 60.8096 & Durbin-Watson Stat. & 0.2017 \\
Prob. (F Statistic) & $1.4232 \mathrm{E}-193$ & & \\
\hline
\end{tabular}

Source: Analysis Output

Table 6 above shows the model summary computed using the unweighted fixed effects specifications as seen in the table 6 , sample: 1987 - 2016, Periods included: 30, Cross-section included: 20, Total panel (balanced) observations: 600, estimation method: Panel Least squares and that the estimated values of the parameters (Constant, BM, EXP, GDP and PCE) 
are $71.4449,-0.1735,-0.3309,7.4338 \mathrm{E}-12$ and $1.1335 \mathrm{E}-10$ respectively and all these estimated parameters are significant at $5 \%$ level except GDP. The value for the estimated coefficient of determination $\left(\mathrm{R}^{2}\right)$ is 0.8525 , meaning that $85.3 \%$ of the total variation in CPI could be explained by the variation in BM, EXP, GDP and PCE, while only $14.7 \%$ could be explained by other variables not included in the model.

Hence, the model is fitted below as:

$$
\hat{Y i t}=71.4449-0.1735 \mathrm{X}_{1 \mathrm{it}}-0.3309 \mathrm{X}_{2 \mathrm{it}}+7.4338 \mathrm{E}-12 \mathrm{X}_{3 \mathrm{it}}+1.1335 \mathrm{E}-10 \mathrm{X}_{4 \mathrm{it}}
$$

OR

$$
\mathrm{CPI}_{\mathrm{it}}=71.4449-0.1735 \mathrm{BM}_{\mathrm{it}}-0.3309 \mathrm{EXP}_{\mathrm{it}}+7.4338 \mathrm{E}-12 \mathrm{GDP}_{\mathrm{it}}+1.1335 \mathrm{E}-10 \mathrm{PCE}_{\mathrm{it}}
$$

The probability values show that values show that BM, EXP and PCE are all statistically significant, while GDP is not significant. It is worthy to note that all variables are not measured in the same unit. The average estimated CPI for the selected sub-Sahara African countries was 59.76. A percentage increase in Broad Money and Export rate brings about a decrease of $17.35 \%$ and $33.0 \%$ in CPI respectively while a $1 \%$ increase in GDP and PCE brings about an increase in the CPI. The coefficients of the fixed effects model are linear, unbiased, consistent as well as efficient. The assumption of the fixed effects model that the residual term should be normally distributed with mean zero and variance $\sigma^{2}$ is satisfied. The idiosyncratic error term of the fixed effect model is distributed with mean zero and variance $\sigma^{2}$.

Table 7. Cross Section Fixed Effect Estimate.

\begin{tabular}{lllllll}
\hline Country & Effect & Country & Effect & Country & Effect & Country \\
\hline 1 & 7.398842 & 6 & 29.29308 & 11 & -12.0251 & 16 \\
2 & -16.2088 & 7 & -18.7099 & 12 & 20.74564 & 17 \\
3 & 20.8374 & 8 & 8.590593 & 13 & -8.49346 & 18 \\
4 & 11.35805 & 9 & 9.741221 & 14 & -8.49346 & -10.312 \\
5 & 11.12784 & 10 & -12.6288 & 15 & -12.3549 & 20 \\
\hline
\end{tabular}

Table 7 shows the cross section fixed effects one way error component (Ui) associated with each cross section. In order to test if the model is good enough for forecasting or whether the coefficient of determination is a spurious one, one needs to test whether or not the cross section effect is significant.

\begin{tabular}{|c|c|c|c|c|c|}
\hline & C & BM & EXP & GDP & PCE \\
\hline $\mathrm{C}$ & 12.17076 & -0.17477 & -0.23163 & $-1.02 \mathrm{E}-11$ & $-6.84 \mathrm{E}-12$ \\
\hline $\mathrm{BM}$ & -0.17477 & 0.006188 & 0.00041 & $1.85 \mathrm{E}-13$ & $-2.67 \mathrm{E}-13$ \\
\hline EXP & -0.23163 & 0.00041 & 0.007408 & $2.19 \mathrm{E}-13$ & $-1.33 \mathrm{E}-14$ \\
\hline GDP & $-1.02 \mathrm{E}-11$ & $1.85 \mathrm{E}-13$ & $2.19 \mathrm{E}-12$ & $6.70 \mathrm{E}-22$ & $-8.13 E-22$ \\
\hline PCE & $-6.84 \mathrm{E}-12$ & $-2.67 \mathrm{E}-13$ & $-1.33 \mathrm{E}-14$ & $-8.13 \mathrm{E}-22$ & $1.61 \mathrm{E}-21$ \\
\hline
\end{tabular}

Table 8. Variance Covariance Matrix.

Table 8 shows the variance covariance matrix and it shows that the variance of the Constant $\mathrm{C}$ is 12.17076 , the variance of $\mathrm{BM}$ is 0.006188 , the variance of EXP is 0.007408 , the variance of GDP is $6.70 \mathrm{E}-22$, and the variance of Private Consumption is $1.61 \mathrm{E}-21$. Their covariance is shown in the intersection of the rows and columns of any two variables.

Table 9. Correlation Matrix.

\begin{tabular}{llllll}
\hline & CPI & BM & EXP & GDP & PCE \\
\hline CPI & 1 & 0.218051 & 0.099302 & 0.235513 & 0.270677 \\
BM & 0.218051 & 1 & 0.108711 & 0.338823 & 0.261655 \\
EXP & 0.099302 & 0.108711 & 1 & 0.020612 & -0.09688 \\
GDP & 0.235513 & 0.338823 & 0.020612 & 1 & 0.770965 \\
PCE & 0.270677 & 0.261655 & -0.09688 & 0.770965 & 1 \\
\hline
\end{tabular}

Table 9 shows the correlation matrix and it shows the maximum correlation coefficient and among the explanatory variable is 0.77 exists between PCE and GDP which is strong positive correlation in contrary to our expectation.
Table 10. Correlation Matrix.

\begin{tabular}{llllll}
\hline & BM & EXP & GDP & PCE & RESID \\
\hline BM & 1 & 0.108711 & 0.338823 & 0.261655 & $3.76 \mathrm{E}-15$ \\
EXP & 0.108711 & 1 & 0.020612 & -0.09688 & $-2.31 \mathrm{E}-15$ \\
GDP & 0.338823 & 0.020612 & 1 & 0.770965 & $-4.53 \mathrm{E}-16$ \\
PCE & 0.261655 & -0.09688 & 0.770965 & 1 & $3.13 \mathrm{E}-16$ \\
RESID & $3.76 \mathrm{E}-15$ & $-2.31 \mathrm{E}-15$ & $-4.53 \mathrm{E}-16$ & $3.13 \mathrm{E}-16$ & 1 \\
\hline
\end{tabular}

Table 10 shows that the explanatory variables in $\mathrm{X}$ are dependent of the idiosyncratic error term. This is because the correlation between the explanatory variables and the idiosyncratic error term is zero (0). Hence, they are not correlated whatsoever.

\section{Conclusion}

It is evident from the data and the analysis that inflation in sub-Sahara African countries is on the high side. This is observed from the incessant increase in the CPI which is a measure of the changes in the price level of market basket of 
consumer goods and services purchased by households including foreign goods. Therefore, for sub-Sahara African countries to experience a pickup in economic growth the following recommendations based on this study should be considered.

Unless there is a significant recovery in commodity prices, there could not be a significant growth. Policy makers most especially in the 8 oil exporting countries should take advantage of lower prices to eliminate fuel subsidies and put in place flexible energy pricing mechanisms since it appears that majority of the sub-Sahara African countries depend largely on oil.

Broad Money is a measure of money supply that includes more than just physical money. It includes demands deposits at commercial banks and any monies held in easily accessible accounts. It has been found to have a significant effect on the CPI. The result show that there is a negative relationship between Broad Money and Consumer Price Index; an increase in Broad Money brings about a decrease in the CPI. This is not in accordance with economic theory which stipulates that there should be a positive relationship between the two indicators. It is therefore advisable that there should be an efficient monetary policy in place in other to strike a balance between Broad Money and CPI. A reduction in money supply will definitely bring about a reduction in prices of goods and services.

The major export commodity of some of the SSA countries is oil, policy makers should because of this make fiscal adjustment a priority by allowing exchange rate to depreciate, where flexible exchange rate mechanisms are in place. Frontier markets must also remain vigilant to avert the risk of disorderly capital movements especially in response to U.S. monetary policy.

Increase in Consumer Price Index brings about increase in inflation which reflects a reduction in the purchasing power per unit of money. Therefore an increase GDP will bring about reduction in prices of goods and services. The deteriorating security situation in some areas of SSA could strain budgets and have adverse impacts on the economic growth especially in the agricultural sector while weakening prospects for foreign direct investments. The government in these nations should therefore put up an effective security measure to have a stable political environment that will foster durable and inclusive economic growth.

If there is decrease in prices the purchasing power of the local currency will increase and this will bring about increase in Private Consumption Expenditure. Efforts should therefore be made to put in place an efficient monetary policy that will bring Consumer Price Index to a minimum.

For there to be a reasonable economic growth, there must be a decrease in CPI, therefore proper attention must be given to the nations' Broad Money, Export Rate, GDP and Private Consumption Expenditure since $85.3 \%$ of this can be achieved through them.

\section{References}

[1] Akpanta, A. C. and Okoric, I. E (2015); on Time Series Analysis of Consumer Price Index data of Nigeria - 1996 to 2013. American Journal of Economics 2015, 5 (3): 363-369.

[2] Umeora, Chinweobo Emmanuel (2010); Effects of Money Supply and Exchange Rates on Inflation in Nigeria. Journal of Management and Corporate Governance, Vol. 2, December, 2010 .

[3] Nguyen, H. M., Cavoli, and Wilson, J. K "The determinants of inflation in Vietnam, 2001 - 2009," Asean Economic Bulletin, vol. 29, no. 1, pp. 1, 2012.

[4] Saravanan Venkadasalam (2015); The Determinant of Consumer Price Index in Malaysia. Journal of Economic, Business and Management, Vol 3, No. 12.

[5] Gungor Turan and Jona Hoxhaj (2015) Money Supply and Prices Relation in Albanian Economy. Academic Journal of Interdisciplinary studies MCSER Publishing. Rome - Italy vol. 4 NO 351.

[6] Saeed, A. (2007) Inflation and Economic Growth in Kuwait: 1985 - 2005 Evidence from Co - integration Error correction Model. Applied Econometrics and International Development vol. 7-1.

[7] Sweidan O. D. (2004) Does Inflation harm Economic Growth in Jordan? An Econometric Analysis for the period 1970 2000 International Journal of Applied econometrics and Quantitative Studies. Vol. 1-2 pp 41-66.

[8] Shitundu, J. L and Luvanda, E. G. (2000). The Effect of Inflaiton on Economic growth in Tanzania. African Journal of Finance and Management vol. 19-1.

[9] Omoke Philip C. (2010) Inflation and Economic Growth in Nigeria. Journal of Sustainable Development. Vol. 3 NO 2 pp 166.

[10] Anarfo, E. B., Abor, J. Y, Osei, K. A and Gyeke-Dako, A (2019). Monetary policy and financial inclusion in Sub-Sahara Africa using a panel VAR Approach Journal of African Business. 20 (1): 1-8.

[11] Anh D. M, Nguyen, Jemma Dridi, Filiz D. Unsal and oral H. Williams (2015) On the Drivers of Inflation in Sub - Saharan Africa. IMF Working Paper WP/15/189.

[12] Baltagi B. H. and Q. Li (1992); Prediction in the one-way error component model with serial correlation. Journal of Forecasting 11, 561-567.

[13] Baltagi, B. H. (2002); Econometric Analysis of Panel Data. $2^{\text {nd }}$ Edition, New York: John Wiley and Sons.

[14] Bloomberg view.com/articles/ 2015 - 11 - 10/ sub - Saharan Africa thrills.

[15] Hsiao, C. (2003); Analysis of Panel Data. Cambridge University Press, Cambridge. 